\section{Opportunities for the East}

Who is doing what to help Eastern European scientists? And where can an Eastern European scientist look for a new source of funds? What follows provides a guide. But established researchers in Eastern Europe should be aware that the first step is still almost always to find a colleague in the West willing to help support a grant application.

\section{Europe}

European Communities (EC). Future East European involvement in the EC's Framework research programme is being debated, but a decision is not expected for some months. Poland and Hungary may be the first to join, having signed agreements for cooperation in science and technology.

In higher education, TEMPUS, a counterpart to the EC's ERASMUS scheme for the mobility of students between EC member states, is to be approved this week. It will at first include only Poland and Hungary, but is expected to expand to cover the whole of Eastern Europe. The scheme will allow students to travel from East European universities to work at EC universities or in industry for three months to a year. There will also be schemes for university staff to move between East European and EC institutions, and to set up projects linking EC and East European universities. But these are aimed at improving training, and are not research based.

The European Science Foundation (ESF), based in Strasbourg, has members which are public grant-making agencies from EC countries and elsewhere. Hungarian membership will be considered later this year. But individuals from countries not represented may (and do) take part in research networks in fields as different as personal development and polar science.

Scientists from countries not represented by ESF membership also take part in some of the more formal collaborative programmes organized within ESF; at least some local costs arise. The European Training Programme in Brain and Behaviour Research has a series of workshops and offers 30 short-term (up to 3 months) fellowships for people younger than 35 as well as travel grants to meetings. There are also small grants for essentially collaborative research between established neuroscientists in the same field. ESF also provides short-term visiting fellowships (up to two months) in toxicology.

The International Union against Cancer (UICC), based in Geneva, runs a number of schemes for cancer researchers to work abroad, or to set up joint research projects between laboratories in different countries. Young Eastern European molecular biologists may apply to work in other European countries through the European Molecular Biology Organization (EMBO)'s long-term and, exceptionally, short-term fellowships. Like the ESF, UICC and EMBO do not run schemes specific to Eastern Europe.

\section{France}

The French Ministries for Research and Technology (MRT), for Foreign Affairs and for Education have just announced measures to improve research exchanges between French laboratories and researchers in Eastern Europe.

Until now, arrangements have been on an ad hoc basis, between senior researchers. Countries in Eastern Europe were not treated any differently from other countries. This usually meant that few contacts could be established. In 1989, about 250 man-months were paid for in grants by the Ministry for Foreign Affairs for senior researcher exchanges.

Since October last year, the ministry says there has been an "exponential increase" in demand. Fifteen high-level fellowships have been awarded to East European researchers this year and the ministry expects $60-70$ such fellowships to be awarded this year. Similarly, the National Centre for Scientific Research (CNRS) and the National Institute of Medical and Health Research (INSERM) have exchange agreements with the relevant academies of most Eastern European countries, except Albania.

The French government last month adopted an "emergency plan" of aid to Eastern European countries which includes measures to improve exchanges and to offer better opportunities for training of young researchers from these countries.

By the end of 1990, MRT hopes to have made 700 grants for senior researchers, young postdoctoral researchers and a number of technicians and engineers to spend between 3 months and 18 months in France. Further expansion will follow. As a rule, awards to researchers are made on the initiative of the French host laboratory and no mechanism yet exists through which Central and East European researchers can apply directly.

In order to "intensify personal contacts" and exchanges with Eastern and Central European countries, the Ministry for Research and Technology has earmarked FF200,000 each for 20 seminars by the end of the year. Scientists from Eastern Europe will also be able to benefit from a FF3 million fund set up to allow them to attend symposia in France this year.

Other measures put forward by MRT include "twinning" of French laboratories with counterparts in Eastern Europe. MRT is also creating 200 "welcome" posts in French research organizations. These will be valued at FF150,000 each and will allow senior researchers to hold posts for six months, alternating with six months in their home laboratory.

\section{West Germany}

As yet there are few grants available for Eastern Europeans to work on independent or joint projects in their own countries.

Except in the case of East Germany, any such grants are regulated by intergovernmental agreements and are arranged for the most part through the academies on the East European side and the Deutsche Forschungsgemeinschaft (DFG) and Research Ministry (BMFT) on the West German side.

DFG is offering a minimum of DM5 million ( $\$ 3$ million) for around 100 joint projects carried out by at least one East and one West German partner. DFG is making a limited exception to its practice of not paying for scientific equipment, which in West Germany is supplied by the Länder (states). Equipment awarded is nominally delivered to the West German partner, which can pass it on to the East German group.

East Germans at present need to have partners in the West before they can apply for money. But this may soon change and East Germans may be able to apply directly for grants from DFG.

Opportunities are greater for those who would like to travel to West Germany. Researchers may apply for fellowships to the Humboldt Foundation. The fellowships are well paid but competitive - just 30 per cent of applicants succeed. The foundation gave 85 fellowships in the natural sciences from six Eastern European countries in 1988 .

Researchers and professors who would like to spend one to three months at a West German institution or to attend a scientific conference in West Germany can apply to the German Academic Exchange Service (Deutsche Akademische Austauschdienst or DAAD). In 1988, DAAD helped to pay for over 1,000 Eastern European researchers to attend conferences in all fields of humanities and natural science. Students and postdoctoral researchers may apply for one-year grants to work in West Germany.

Last year, the Volkswagen Foundation set up a programme for East German research groups. The foundation offers as much as DM10 million in direct aid to East German researchers and applications have already begun to flow.

Bonn is not the only place to turn for help in West Germany. Several of the West German Länder are offering money to East Germans who wish to attend conferences or collaborate with researchers in those Länder. Baden-Württemberg, for example, is expected to offer about 
DM3.5 million in 1990 for "university, scientific and cultural exchange" with researchers in Saxony, especially in the Dresden region. Other Länder have programmes for their 'partner regions' in the East.

The Research Ministry has also approved DM80 million in extra funds for East German research (much of it applied research) for 1990 . Some of this money may be given to East Germans directly.

\section{United Kingdom}

The Royal Society has exchange agreements with academies of science in all Eastern European countries (except Albania). Apart from the Bulgarian programme, which is not very active, each agreement is nominally for between 12 and 20 person-months of exchange a year, although the programmes are constantly expanding. Some joint research projects, linking East European and UK laboratories, are also supported.

Eastern European scientists can visit the United Kingdom on short 'study visits' or for longer 'fellowships'. The latter are for young postdoctoral researchers, and are being expanded. East European scientists interested in the Royal Society's exchange programmes should apply through their own academy.

The British Council's Cultural Exchange Programmes allow scientists from Bulgaria, Czechoslovakia, East Germany, Hungary and Romania to travel to Britain for short research visits and provides some postgraduate scholarships. Limited funds are also available to foster links between British and Eastern European research groups.

For Poland, the British Council runs an Academic Links Project, financed by the UK Government's 'Know How' Fund. Designed primarily to improve training by linking British and Polish higher education institutions, the scheme includes projects in environmental management and agriculture. Similar schemes for Czechoslovakia and Hungary may be announced soon.

The British Council also administers schemes set up by several other organizations, including the Leverhulme Trust's East European visiting fellowships which allow one postdoctoral scientist a year from each of Bulgaria, Czechoslovakia, Hungary, Poland and Yugoslavia to work in the United Kingdom for up to 10 months.

The Wellcome Trust's European Programme covers all Eastern European countries. Postdoctoral scientists may visit for one year. Application is through a British sponsor. Wellcome also funds shorter research visits. About 20 Eastern European scientists a year visit the United Kingdom under these two schemes, but there are a larger number of travel grants for experienced biomedical researchers to attend UK scientific meetings or learn new techniques.

The Cancer Research Campaign supports visiting fellows at the Patterson Institute for Cancer Research in Manchester. Fellows can come from any country, but the institute has strong links with Eastern Europe. Short visits are preferred, but the budget for 1990-91 is already spent. Experimental cancer researchers interested in visiting the United Kingdom the following year should contact Professor David Harnden but should be aware that competition is severe.

Young Eastern European Scientists should also look out for advertisements (usually in Nature) for bursaries to attend the Ciba Foundation's London symposia. There are about eight symposia a year, on topics in medical and chemical research, and bursars may work in a participant's laboratory for four weeks.

\section{Austria}

The Ministry of Science has received 160 million schilling (about $\$ 14$ million) for scientific cooperation with Eastern Europe in 1990. Part of the money will be used to invite professors from Eastern European countries.

Austria has eliminated fees for students from Hungary and Romania (Czech and Slovak students were always exempt). The Technical University in Vienna plans to create an East-West centre to assist in the transfer of technology.

Austria would like to serve as a liaison for research groups seeking access to large research establishments in Western Europe but the ministry has not yet released details of how this will work.

The ministry says researchers should first turn to the Austrian cultural institutes or embassies in their countries, as well as to their countries' own culture ministries, to get more information about exchanges.

\section{United States}

Attitudes towards the old Eastern bloc are changing rapidly in the United States. This month, the National Institutes of Health (NIH) are considering a grant proposal that has a Moscow-based Soviet scientist as one of it co-principal investigators. If Maxim Frank-Kaminetskii of the Institute of Molecular Genetics in Moscow and Valery Soyfer of Ohio State University are successful, NIH will have given their first direct grant to a scientist in the Soviet Union.

Bigger changes may be on the way, although the slow pace of the US budget cycle still puts the United States far behind West Germany and France in new initiatives to help Eastern European scientists.

Virtually the only new source of money so far approved comes in the Support for East European Democracies (SEED) Act. The act is intended to help Eastern European countries to establish market economies but also provides for several major environmental protection schemes.

Most NIH support for foreign visitors involves the Fogarty International Center. About 170 Eastern European scientists are helped each year. The number is expected to grow as Eastern Europeans develop the contacts needed to secure invitations to work in the United States. The Fogarty Center also runs a postdoctoral fellowship programme and a small two-way exchange programme with Poland, Bulgaria, Romania and Czechoslovakia. Congress may this year approve a major budget expansion that would also provide the first NIH support for collaborative research in Eastern European laboratories.

The National Science Foundation has formal agreements with most East European countries to support cooperative research projects. Each side pays for the expenses incurred in its own country with NSF allowing a total budget of around $\$ 600,000$ a year. Interest in the programmes is running very high and there are hopes for a big increase in next year's budget. NSF is also helping East European countries to establish their own peerreview systems.

The National Academy of Sciences has exchange agreements with each of the East European academies which provide for a certain number of person-months of exchange each year, ranging from 10 in the case of East Germany to 27 for Czechoslovakia. Applications are made through the foreign academies.

The Fulbright Scholar Program is probably the best-known US exchange programme, but there are scholarships for only a handful of scientists each year. Information can be obtained at US embassies abroad.

Hungarian scientists can obtain special help from the Soros Foundation. Set up by George Soros, a wealthy expatriate Hungarian, it offers some 50-100 scholarships and student grants for study abroad through its office in Budapest.

Selected addresses (addresses are not given where the information is better obtained through a local embassy, academy, or a foreign partner.)

United KIngdom. Wellcome Trust, 1 Park Square West, London NW1 4ப $\square$ Professor David Harnden, Patterson Institute for Cancer Research, Christie Hospital, Manchester M20 9BX $\square$ Ciba Foundation, 41 Portland Place, London W1N 4BN.

Belgium. TEMPUS Office, European Commission, Rue de la Loi 200, 1049 Brussels, Beigium.

France. European Science Foundation, 1 Quai Lezay Marnesia, 67000 Strasbourg.

Switzerland. UICC, 3 Rue du Consiel-General, 1205 Geneva, Geneva.

West Germany. EMBO, 6900 Heidelberg 1, Postfach $1022.40 \square$ Deutsche Forschungsgemeinschaft (DFG) Kennedyallee 40, (Postfach 2050 04), Bonn 2 口 Alexander von Humboldt Foundation, Jean-Paul-Str. 12 D-5300 Bonn $2 \square$ Deutsche Akademische Austrauschidientst (DAAD), Kennedyallee 50, D-5300 Bonn $2 \square$ Volkswagen Foundation, Kastanienallee 35, (Postfach 8105 09), D-3000 81.

Austria. Austrian Ministry of Science, Minoritenplatz 5 , A-1014 Vienna $\square$ Technical University of Vienna, Karlsplatz 13, A-1040 Vienna. 